\title{
ACESSO À JUSTIÇA: ASPECTOS PSICOLÓGICOS E JURÍDICOS DA LEI MARIA DA PENHA
}

\author{
Paula Lima Camargo ${ }^{1}$ \\ Raynan Henrique Silva Trentim ${ }^{2}$ \\ Tereza Rodrigues Vieira ${ }^{3}$
}

CAMARGO, P. L.; TRENTIM, R. H. S.; VIEIRA, T. R. Acesso à justiça: aspectos psicológicos e jurídicos da Lei Maria da Penha. Rev. Ciênc. Juríd. Soc. UNIPAR. Umuarama. v. 21, n. 2, p. 149-167, jul./dez. 2018.

RESUMO: A discussão sobre violência doméstica e familiar contra mulheres sempre foi (e ainda é) um tabu, assunto proibido pelo silêncio e pelo "familismo". Desde a infância, as mulheres aprendem a se calar sobre os atos de violência familiar e são condicionadas por uma cultura patriarcal. Porém, muitas barreiras têm sido derrubadas e o assunto tem trazido a curiosidade e a atenção de profissionais da área jurídica, principalmente daqueles que atuam na defesa dos direitos das mulheres. O agressor, geralmente, é homem, muitas vezes é o marido, o que torna este crime algo severamente brutal, pois este conhece as fragilidades e se aproveita da vulnerabilidade da vítima. A obediência à autoridade masculina é incontestável onde há um padrão de convivência e a comunicação não é aberta, o que facilita a confusão da vítima e a dificuldade de procurar ajuda. Além da reconstrução do padrão de relacionamento familiar, também é preciso lidar com os danos deixados pelo abuso, tais como distúrbios nos relacionamentos afetivos, autoimagem rebaixada, depressão e doenças psicossomáticas ou psiquiátricas. Para isso, o serviço de atendimento à mulher vítima de violência deverá ser realizado de forma humanizada, para que atenda às suas expectativas ao invés de causar constrangimento. Destarte, por meio de pesquisa bibliográfica e legislativa, o presente artigo tem por objetivo tecer algumas considerações acerca dos aspectos psicológicos e jurídicos da Lei Maria da Penha e sua incidência sobre as mulheres cisgênero e transgênero. É importante reforçar que cabe aos profissionais da área social e policial estabelecer contato com os equipamentos da rede, sensibilizando e mobilizando a sociedade e tendo sempre em vista que a

DOI: $10.25110 /$ rcjs.v21i2.2018.7499

${ }^{1}$ Graduanda em Direito pela Universidade Paranaense (UNIPAR) e Integrante do Projeto de Iniciação Científica da UNIPAR, Campus Guaíra. E-mail: paulalima0801@hotmail.com

${ }^{2}$ Graduando do Curso de Direito da Universidade Paranaense (UNIPAR), Integrante do Programa de Bolsas de Iniciação Científica da UNIPAR, Campus Sede e Graduando do Curso de História da UNINTER, E-mail: raynantrentim@hotmail.com

${ }^{3}$ Pós-Doutora em Direito pela Université de Montreal, Canadá; Docente do Mestrado em Direito Processual e Cidadania da Universidade Paranaense (UNIPAR). 
vítima emite sinais indicados pela violência sofrida, portanto, devem estar sempre preparados e atentos, para saber ouvir, respeitar e acreditar em sua fala. PALAVRAS-CHAVE: Educação; Empoderamento; Gênero; Violência; Vulnerabilidade.

\section{ACCESS TO JUSTICE: PSYCHOLOGICAL AND LEGAL ASPECTS OF THE MARIA DA PENHA LAW}

ABSTRACT: The debate regarding domestic and family violence against women has always been (and still is) a taboo, a forbidden matter surrounded by silence and family traditions. Since childhood, women have learned to become silent regarding family violent acts and are conditioned by a patriarchal culture. Nevertheless, many barriers are now starting to be overturned, with the matter coming into attention and leading to the curiosity and attention of professionals in the area, especially those who work in defending women's rights. The aggressor is usually a man, many times the actual husband, which makes this crime something extremely brutal because he knows her weaknesses and takes advantage of the victim's vulnerability. Obedience to male authority is incontestable where there is a pattern of coexistence and where communication is not open. This makes it easy to confuse the victim and hinder her search for help. Besides the reconstruction of the family relationship pattern, it is also necessary to deal with the damages left by the abuse, such as disturbances in future relationships, low self-esteem, depression and psychosomatic or psychiatric illnesses. In those cases, the victims reporting abuse must be seen in an empathetic way, meeting the woman's expectations instead of causing further embarrassment. This study also verifies the incidence of the Maria da Penha Law on both cis- and transgender women. Therefore, it is important to emphasize that it is the responsibility of social and law enforcement professionals to establish contact with the network equipment, sensitizing and mobilizing the society, reminding them that the victim sends out signs indicating the violence she has been suffering and, for that reason, they must always be prepared and attentive, knowing how to listen, respect and believe in the victim's report.

KEYWORDS: Education; Empowerment; Gender; Violence; Vulnerability.

\section{A LA JUSTICIA: ASPECTOS PSICOLÓGICOS Y JURÍDICOS DE LA LEY MARÍA DA PENHA}

RESUMEN: La discusión sobre la violencia doméstica y familiar contra mujeres siempre fue (y aún es) un tabú, asunto prohibido por el silencio y las tradiciones de la familia. Desde la infancia, las mujeres aprenden a callarse sobre 
los actos familiares violentos y están condicionadas por una cultura patriarcal. Sin embargo, muchas de las barreras han sido derribadas, y el asunto ha traído la curiosidad y la atención de profesionales del área jurídica, principalmente de aquellos que actúan en la defensa de los derechos de las mujeres. El agresor generalmente es hombre, muchas veces es el marido, lo que hace de este crimen algo severamente brutal, pues éste conoce las fragilidades y se aprovecha de la vulnerabilidad de la víctima. La obediencia a la autoridad masculina es incontestable donde hay un estándar de convivencia y la comunicación no es abierta, lo que facilita la confusión de la víctima y la dificultad de buscar ayuda. Además de la reconstrucción del estándar de relación familiar, también hay que lidiar con los daños causados por el abuso, tales como disturbios en las relaciones afectivas, autoimagen rebajada, depresión y enfermedades psicosomáticas o psiquiátricas. Para eso, el servicio de atención a la mujer víctima de violencia deberá ser realizado de forma humanizada, para que atienda a sus expectativas, al revés de causarle constreñimiento. De esta forma, por medio de investigación bibliográfica y legislativa, este artículo ha tenido por objetivo mencionar consideraciones acerca de los aspectos psicológicos y jurídicos de la Ley Maria da Penha y su incidencia bajo las mujeres cisgénero y transgénero. Es importante reforzar que corresponde a los profesionales del área social y policial establecer contacto con los equipos de la red, sensibilizando y movilizando la sociedad, teniendo en cuenta que la víctima emite señales indicadores de la violencia sufrida, por lo tanto, deben estar siempre preparados y atentos, para saber escuchar, respetar y creer en su habla.

PALABRAS CLAVE: Educación; Empoderamiento; Género; Violencia; Vulnerabilidad.

\section{INTRODUÇÃO}

A violência doméstica continuamente esteve presente na sociedade, fazendo com que as mulheres se tornassem vítimas de agressões físicas, psicológicas e sexuais. Em razão da vulnerabilidade ocasionada, por vezes, pela dependência emocional e econômica em relação ao agressor, muitas se calam perante tais situações.

Durante muito tempo, a sociedade patriarcal sustentou a ideia de vulnerabilidade e submissão das mulheres aos homens, sendo que apenas após incontáveis mortes em decorrência da violência doméstica foi que o Estado compreendeu a devida gravidade deste crime e se empenhou para coibir tal conduta delituosa, tipificada pela Lei 11.340/2006 (Lei Maria da Penha).

Destarte, necessário é levantar algumas reflexões básicas acerca desta importante temática, tais como: qual a abrangência da Lei Maria da Penha 
(11.340/2006)? Por que as mulheres suportam, por tanto tempo, a violência doméstica? Que tipos de violência doméstica e familiar incidem contra as mulheres? A violência contra a mulher atinge bens jurídicos de dimensão pública ou eles se circunscrevem apenas na esfera privada e meramente familiar? A falta de capacitação dos agentes públicos é algo que colabora para que as mulheres ainda pouco procurem a assistência do Estado? Quais seriam os meios de prevenção e conscientização que quebrariam os paradigmas culturais de uma sociedade machista e patriarcal? Os agentes políticos e a sociedade civil têm contribuído para o empoderamento da mulher? Aplicam-se às mulheres transexuais o disposto na Lei Maria da Penha e nas normas que qualificam o crime de Feminicídio? Por meio de pesquisa bibliográfica de doutrina, decisões jurisprudenciais e produção legislativa, pretende-se responder a estas e outras importantes questões acerca do tema.

De início, é necessário destacar que, embora o enfrentamento da agressividade doméstica seja um assunto de grande relevância social, este encontra um grande obstáculo, representado pela separação daquilo que é público e do que é parte da vida privada do casal. Além disso, a falta de informação acerca dos benefícios e da tutela da Lei Maria da Penha faz com que as mulheres se sintam, inúmeras vezes, desprotegidas pelo Estado, tendo receio de procurar ajuda e de não ter resguardo suficiente, e pior, perder os seus direitos como mãe e também sobre o seu patrimônio.

\section{BREVE RETROSPECTIVA HISTÓRICA}

Desde os primórdios, as mulheres carregaram o dever de cuidado do lar, assumindo, assim, as responsabilidades dos papéis de esposa, mãe e doméstica. No entender de Jenainati e Groves (2018, p. 126):

el patriarcado es responsable de construir un sistema social que atribuye determinado estatus sexual, rol y rasgos de comportamiento a cada gênero, asegurando de este modo la jerarquía sexo/gênero. Como resultado de ello, se atribuyen rasgos "masculinos" a los roles sociales dominantes mientras que "lo femenino" queda asociado a la sumisión y a la dependencia.

As famílias criavam as mulheres para se casar e cuidar do lar, enquanto os homens sempre foram criados para trabalhar fora. Dessa forma, as meninas tinham por obrigação serem boas mães, enquanto os meninos eram treinados para exercer autoridade sobre as "futuras esposas".

A naturalização do patriarcado fez com que as mulheres se tornassem 
anestesiadas por um período de tempo, em que os opressores prezavam pelos costumes e pela continuidade da cultura humana, e a mulher tinha o dever de ser submissa ao homem.

Prova disso é que no Brasil, até 1827, as mulheres não podiam frequentar o ensino elementar, circunstância que somente foi alterada com a publicação da primeira Lei Geral concernente ao assunto:

Art. 11. Haverão escolas de meninas nas cidades e vilas mais populosas, em que os Presidentes em Conselho, julgarem necessário este estabelecimento.

Art. 12. As Mestras, além do declarado no Art. 6o, com exclusão das noções de geometria e limitado à instrução de aritmética só as suas quatro operações, ensinarão também as prendas que servem à economia doméstica; e serão nomeadas pelos Presidentes em Conselho, aquelas mulheres, que sendo brasileiras e de reconhecida honestidade, se mostrarem com mais conhecimento nos exames feitos na forma do Art. 7o.

Art. 13. As Mestras vencerão os mesmos ordenados e gratificações concedidas aos Mestres. (BRASIL, 1827).

Ainda, somente após mais de cinquenta anos da promulgação da referida Lei é que as mulheres receberam a tão esperada autorização do governo para estudar em instituições de Ensino Superior, porém, enfrentaram muita oposição social. Afinal, compreendia-se que suas obrigações se restringiam, exclusivamente, aos cuidados domésticos.

Antes da Lei Maria da Penha, poucas eram as políticas estatais para a proteção das mulheres. Cite-se que apenas em 1985 é que foi criada a primeira Delegacia de Atendimento Especializado à Mulher - DEAM (SP) e, no mesmo ano, a Câmara dos Deputados aprovou o Projeto de Lei que criou o Conselho Nacional dos Direitos da Mulher (CNDM).

Ao ponderar a história da mulher brasileira, é possível perceber alguns avanços na conquista da igualdade de gênero, como por exemplo, o direito à educação, à capacidade civil e direito ao voto. Porém, a agressão doméstica, continuamente, esteve presente no âmbito familiar. Logo, mesmo diante dos avanços políticos, as consequências advindas do patriarcado ainda persistem, o que certamente influencia nas ocorrências de violência contra a mulher.

\section{A LEI MARIA DA PENHA}

A Lei Maria da Penha surgiu com o intuito de criar mecanismos que coibissem as agressões contra a mulher no âmbito doméstico e familiar. Em 2006, 
a Lei 11.340 estabeleceu que a violência doméstica é uma violação dos direitos humanos, inclusive, sua ocorrência determina o cumprimento de procedimentos de acolhimento pelas autoridades e órgãos responsáveis pelo atendimento à mulher, de forma prioritária.

Ademais, garante que a mulher receba tratamento médico gratuito e tratamentos especiais em episódios de violência sexual. O magistrado poderá determinar que a mulher seja incluída em programas de assistência mantidos pelo governo, tais como: bolsa-família, garantia de vagas em escolas e creches para seus filhos e programas de cestas básicas, sendo este o realce do artigo $3^{\circ}$ desta Lei, o qual dispõe que:

serão asseguradas às mulheres as condições para o exercício efetivo dos direitos à vida, à segurança, à saúde, à alimentação, à educação, à cultura, à moradia, ao acesso à justiça, ao esporte, ao lazer, ao trabalho, à cidadania, à liberdade, à dignidade, ao respeito e à convivência familiar e comunitária. (BRASIL, 2006).

Diante da leitura deste dispositivo é evidente que a Lei impõe ao Estado o dever de assegurar à mulher todos os direitos citados e de punir aqueles que os desrespeitarem.

Ademais, prevê a elevação da pena máxima da lesão corporal doméstica, removendo a condenação de menor potencial ofensivo e acabando com a banalização da violência doméstica em no Brasil. Conforme Nilo Batista (2001), a promulgação da referida Lei foi responsável por provocar um grande debate sobre o tema da violência doméstica - apesar de tal atribuição não ser o que se espera das leis se o debate não se sustentar em instâncias políticas e culturais que devem mantê-lo e aprofundá-lo.

Assim, razão assiste à Flávia Biroli (2018, p. 210), ao afirmar que:

Violência cotidiana e violência política interligam-se em práticas que pressionam as mulheres para permanecer naquele que seria "seu lugar"- ou a ele retornar -, isto é, os espaços domésticos-familiares, a aceitação de formas menos ou mais diretas de tutela masculina. Os obstáculos no acesso a recursos e a coerção mais direta, que a violência política põe em ato, não se misturam apenas aos estereótipos depreciativos. A qualificação do feminino como docilidade e domesticidade, que intensifica nos estereótipos materiais e no "familismo", situa as mulheres no mundo de um modo que torna natural sua ausência dos espaços 
decisórios. É algo que pode ser também reproduzido nos meios de comunicação, que espelham e ao mesmo tempo colaboram para reproduzir essas relações.

É inegável que a Lei Maria da Penha é resultado de uma luta histórica pela busca da efetividade do princípio da isonomia, sendo certo que confere maior proteção às mulheres vítimas de violência doméstica e familiar. A Lei também implanta métodos mais céleres e eficazes na tutela dessas mulheres. (SÁ JUNIOR, 2019).

Conforme compreende Luís Irajá Nogueira de Sá Junior (2019, p. 614), durante muito tempo a doutrina e a jurisprudência divergiam no conceito do termo "mulher", para uns, mulheres seriam apenas aquelas que possuem sexo biológico feminino ou que fossem registradas como do sexo feminino em seus assentos civis. Já para outros, mais conectados com a realidade social do país, a expressão "mulher" deveria abranger toda pessoa que se identifica como do sexo feminino, ainda que seu sexo biológico seja outro, mesmo sem a devida alteração registral.

Nesse contexto, é inegável que a mulher transexual, quando assume socialmente a sua identidade, encontra-se vulnerável frente à sociedade. Portanto, essa também deve ser entendida como merecedora de direito, uma vez que a Lei Maria da Penha nasceu no ordenamento jurídico para coibir a violência de gênero, já que os papéis impostos à mulher, até então, eram excludentes e proclamavam a figura masculina heteronormativa como superior às mulheres, mulheres trans e gays.

Logo, em uma relação familiar doméstica ou de convivência onde houver essa desigualdade deve ser aplicada à referida Lei, pois a violência, nesses casos, ocorre por razões de gênero. A doutrina contemporânea, assertivamente, aceita a possibilidade de aplicação da Lei Maria da Penha para transexuais e homossexuais devido a sua vulnerabilidade intrafamiliar e pelo fato de que sofrem todos os tipos de violências em decorrência de sua identidade de gênero ou orientação sexual.

Nas palavras de Bianchini (2014, p. 420):

A violência de gênero envolve uma determinação social dos papéis masculino e feminino. Toda a sociedade pode (e talvez até deva) atribuir diferentes papeis ao homem e à mulher. Até aí tudo bem. Isso, todavia, adquire caráter discriminatório quando a tais papeis são atribuídos pesos com importâncias diferenciadas. No caso da nossa sociedade, os papeis masculinos são supervalorizados em detrimento dos femininos. 
A autora chama a atenção no sentido de que para a aplicação da Lei Maria da Penha, além da violência ter por base a questão de gênero, não se pode perder de vista a exigência de que sua ocorrência se dê no ambiente doméstico ou familiar, que nutra uma relação íntima de afeto. Assim, verifica-se que todos estes requisitos podem estar perfeitamente presentes no caso de violência contra transexuais ou homossexuais (BIANCHINI, 2014). Ademais, a Lei Maria da Penha aplica-se nas relações de violência de gênero no âmbito familiar, como demonstraremos a seguir, abarcando mulheres transgênero, por serem mulheres. E, mesmo se assim não fosse, também estariam amparadas pela Lei nos casos em que a violência no ambiente familiar ocorresse de forma determinante pelo gênero.

\subsection{O ciclo da violência}

A violência doméstica, segundo Lenore Walker (1979), segue um padrão composto por três fases: a criação da tensão, o ato de violência e a fase amorosa. No entanto, a última fase tende a não durar muito, fazendo com que o ciclo se repita.

Na primeira fase iniciam-se as agressões de menor potencial agressivo, por meio de xingamentos e crises de ciúmes. Gradualmente, há um aumento de tensão, fazendo com que esses atos se potencializem. A vítima, por outro lado, tenta justificar as atitudes do agressor, alegando fatores como o cansaço, a falta de dinheiro e, por vezes, tende a romantizar o ciúme e a possessividade como desculpa, se tornando assim cada vez mais passiva e retraída.

Com o tempo, as agressões se tornam mais sérias e violentas, levando o ciclo à fase dois. Esta pode ser representada pela violência física, psicológica, moral, sexual e patrimonial. A agressão física ocorre nos casos em que há um contato físico entre a agredida e o agressor, que deixa a mulher com o corpo machucado ou com problemas de saúde. Qualquer lesão que seja provocada pelo algoz, por menor que seja, ou que ainda não deixe nenhuma marca (puxões, empurrões), ameaças, humilhações, ou que obrigue a mulher a manter ou presenciar relação sexual não desejada, é exemplo de violência psicológica, moral e sexual, respectivamente, e tal situação culminará em ato potencialmente agressivo. $\mathrm{Na}$ última fase do ciclo, após a explosão da segunda fase, o agressor se apresenta arrependido, amoroso e gentil, fazendo com que a vítima se convença de que ele mudará o seu comportamento violento. (WALKER, 1979), E assim, o ciclo se inicia novamente.

\subsection{O rompimento do ciclo}

Existem muitas razões para que as mulheres não consigam romper com 
o ciclo criado dentro de um relacionamento abusivo e violento. Muitas vítimas temem o rompimento, porque consideram que o máximo de todos os riscos é justamente o cessar da relação. Além disso, diante das agressões sofridas, procurar ajuda, muitas vezes, ainda é visto como vergonha e constrangimento perante a sociedade.

No entanto, romper o ciclo de violência é fundamental para que a mulher que está em uma relação de opressão se liberte. Sobre esse tema, Cazelatto e Cardin (2018) fundamentam que a liberdade é considerada um dos bens e, ao mesmo tempo, uma das qualidades mais iminentes da condição humana. É ela que permite ao indivíduo vivenciar ou transmitir a sua própria identidade, os seus pensamentos, o seu ir e vir, além de viabiliza a atividade de inúmeros outros atributos ou direitos.

Nesse viés, Cazelatto e Cardin (2018, p. 75) concluem que:

por envolver influências de caráter axiológico, teológico, filosófico, antropológico, cultural, político e econômico, a sua conceituação recebe os mais diversos significados conforme a finalidade para qual será empregada. Em virtude dessa fluidez, é importante verificar inicialmente a proteção e a extensão outorgadas às liberdades jurídicas, com especial atenção à liberdade de expressão e às demais liberdades que com esta se correlacionam ou se contrapõem.

Infelizmente, muitas mulheres sofrem caladas e, por vezes, são silenciadas por seus parceiros ou ex-parceiros. Ainda, é indiscutível a dificuldade de que a vítima tem de se libertar de tais condutas do agressor, pois não há como determinar um ponto específico do perfil da pessoa que está sendo oprimido, uma vez que a violência se dá por vários motivos, conforme retromencionado.

Algumas vítimas alimentam a esperança de que o companheiro mude o seu comportamento, pois, inúmeras vezes, está isolada dos serviços oferecidos pelo Estado. Ademais, algumas mulheres dependem economicamente de seus parceiros, o que torna a situação mais complexa, pois a agredida sente medo de perder os seus direitos e também de não conseguir se reerguer ou se sustentar, visto que talvez venha a passar necessidades básicas. Assim, deixar uma relação violenta é um processo, no qual cada um possui o seu tempo.

Quando criança, as meninas são impostas à submissão do homem. Os primeiros brinquedos comprados são bonecas, uma vez que a maioria das mulheres ainda é criada para procriar e cuidar da casa, influenciadas a serem subordinadas e a sonharem pelo dia que casarão e servirão ao seu marido. Por outro lado, a maior parte dos meninos ganha bolas de futebol, carros de brinquedo e, 
quando um pai fala com o filho, ele articula como o garoto deve ser o provedor da casa, sobre o seu crescimento intelectual, e, em poucas famílias lhe é ensinado algo sobre o casamento.

E assim, cria-se uma dependência emocional, pois as mulheres são criadas para casar, enquanto os homens para explorar o mundo, fazendo com que haja uma divergência de pensamentos, em que a própria parte feminina se subestima ao aceitar o comportamento dos homens. Em uma de suas citações, Simone Beauvoir (2000) proclama que "a humanidade é masculina e o homem define a mulher não em si, mas relativamente a ele; ela não é considerada um ser autônomo". Constatação lamentável, mas verdadeira para a maioria.

\section{O ACESSO À JUSTIÇA}

As medidas de proteção à mulher citadas pela Lei Maria da Penha são tomadas em caráter de urgência para interromper toda e qualquer violência, impedindo o agressor de se aproximar da agredida. A mulher poderá procurar atendimento por meio de ligação para as centrais de atendimento à mulher ou em delegacias especializadas (as DEAM), Defensorias Públicas e Ministério Público. Independentemente do órgão procurado, haverá um encaminhamento para a delegacia para que se efetue a ocorrência policial relatando a violência sofrida.

$\mathrm{Na}$ delegacia será providenciado o registro da ocorrência na forma indicada pela Lei Maria da Penha, com proteção policial quando necessária, orientação e informações sobre os direitos e os serviços disponíveis para a proteção da mulher.

\subsection{Dificuldades no sistema de atendimento}

Após vencer o medo de falar sobre os seus problemas e sobre as suas particularidades, a mulher, no seu tempo, cansa de se calar. Porém, por vezes, ao ir até uma delegacia, local onde deveria receber suporte, apoio e empatia, ela se depara com profissionais despreparados, que debocham, insinuam práticas ofensivas à vítima, fazendo-a "reviver" as agressões em razão da repetição contínua dos fatos.

Silvia Chakian, Promotora de Justiça (2016), reconhece que esse é o maior empecilho à eficiência da Lei Maria da Penha, tendo afirmado que os agentes públicos - da polícia e até do judiciário - são membros de uma sociedade machista e, às vezes, reproduzem esses estereótipos no atendimento dessas mulheres. (MENDONÇA, 2015) Portanto, esses agentes carecem de capacitação.

Com o intuito de abrandar essa questão, o Governo Federal, em 2013, lançou o programa "Mulher, Viver Sem Violência", tendo como um de seus fins, capacitar policiais e agentes públicos, em geral, para acolher as mulheres vítimas 
de violência de maneira mais humanizada.

Ademais, criou-se também unidades denominadas de "Casa da Mulher Brasileira", lugares que unificam no mesmo espaço serviços particularizados para os diferentes tipos de violência contra a mulher: acolhimento, delegacia, Ministério Público, etc. Desde 2013, foram instituídas algumas unidades pelo país. (MENDONÇA, 2015).

Outro fato que impede os efeitos da Lei 11.340/2006 é a complexidade de provar a violência, requisito que comumente evita a concretização de justiça a essas mulheres. No Canadá, por exemplo, a legislação avançou com o movimento "Yes Means Yes" (Sim significa sim), que prega que o consentimento para relações sexuais precisa ser expresso e afirmativo. Logo, se a vítima não dá evidências de consentimento e não colabora para a relação, é caso de estupro. Por exemplo, que o fato de a mulher estar embriagada, com os braços repousados, não quer dizer que ela está consentindo. (MENDONÇA, 2015).

O problema em comprovar a violência repercute nos números que confrontam dados de denúncias com o de agressores punidos, como se percebe do Levantamento Nacional de Informações Penitenciárias (INFOPEN, 2016), que assevera que 2.439 homens estavam presos por crimes de violência doméstica até junho de 2014. Em 2014, 52.957 mulheres denunciaram episódios de violência - entre eles violência física, psicológica, moral, sexual, etc. -, em torno de 145 por dia. (MENDONÇA, 2015)

Por conseguinte, para as autoridades, esta falta de provas atribui uma falta de confiabilidade na palavra da vítima, acarretando-lhe ainda mais dificuldades.

\subsection{A Lei 13.050 de 2017: da revitimização e da busca por um depoimento sem dano à vítima}

As pessoas que integram as agências executivas, em geral, pertencem, segundo Zaffaroni (1991), aos mesmos segmentos sociais onde são aliciados os criminalizados e os vitimados pelo sistema penal e suportam violações de direitos humanos tão deteriorantes quanto os criminalizados e vitimizados, Em função de sua situação anômica, sofrem uma perda de identidade original e assunção de uma identidade artificial, gerada pelo seu treinamento de acordo com um "discurso externo moralizante", porém, não raro, basilar de uma "prática interna corrupta".

Ademais, os policiais que trabalham diretamente com as vítimas de violência doméstica devem estar preparados para adotar um comportamento humanizado, que não reforce situações traumáticas vivenciadas pelas vítimas, deixando assim de lado, o papel de 'macho' policializado, que não tem medo, ou sensibilizado, construído na sua capacitação. 
Desse modo, a má capacitação dos agentes públicos responsáveis pelos acolhimentos de mulheres é uma dos motivos pelos quais as mulheres que sofrem violência doméstica não tornam a buscar ajuda, pois se sentem constrangidas e envergonhadas de terem que narrar os fatos vivenciados. Além do receio do julgamento de seus respectivos ouvintes, por vezes, empáticos, fato que dificulta o apoio à mulher após esta difícil tomada de decisão de não mais se manter calada.

O artigo $1^{\circ}$ da Lei 13.050/2017 proclama acerca do direito de a mulher em situação de violência doméstica e familiar ter atendimento policial e pericial especializado, ininterrupto e prestado, preferencialmente, por servidores do sexo feminino. O que garantiria, "em tese", maior sensibilidade advinda por parte do servidor.

A Lei ainda determina a capacitação da pessoa que perpetrará o atendimento das vítimas. Deve o Estado, destarte, capacitar seus servidores públicos, principalmente, os do sexo feminino, que deverão realizar, preferencialmente, o atendimento à mulher vítima de violência doméstica e familiar. Essa habilitação, aliás, deve ser realizada pelos Estados e Distrito Federal, segundo dispõe o art. 12-A, caput da Lei supracitada.

\section{5 - DA APLICAÇÃO DA LEI MARIA DA PENHA PARA MULHERES TRANSGÊNERO}

É sabido que o Direito tem origem de uma demanda social, visto que onde há fatos é necessário que a norma nasça para regular essas relações. $\mathrm{O}$ direito, por vezes, tem por base conceitos oriundos de outras áreas para regulamentar condutas, em que descreve e recrimina, cominando penas, como no caso do direito penal.

A transexualidade, conhecida e descrita por muitos estudiosos da área, como transgênero, é reconhecida pela Medicina e Psicologia como existente nos casos em que a pessoa trans se sente "no corpo errado" e, é necessário que esta se ajuste ao seu gênero, transitando para o gênero psíquico. Desta forma, grande parte dos profissionais da saúde reconhecem essa situação e consideram a mulher trans como mulher, independente de sua genitália.

Partindo da premissa de que a Medicina e a Psicologia são as áreas de conhecimento mais competentes para analisar o caso da transexualidade e de como estes corpos se determinam na sociedade, o direito deve partir dessas conclusões e adequá-las ao caso concreto, não por analogia, mas sim tendo em vista situações fáticas.

A Lei Maria da Penha defende as mulheres vítimas de violência doméstica, sendo de fácil constatação que mulheres trans estão abarcadas por essa Lei e, já que a Medicina determina que estas são mulheres, não cabe aos operadores 
do direito dizer o que é um corpo feminino ou masculino, já que isso foge dos conhecimentos abrangidos por sua área profissional, e sim analisar o caso concreto e verificar a vulnerabilidade feminina.

Nesse sentido, não é de hoje que a Medicina, por meio da Organização Mundial da Saúde e do Conselho Federal de Medicina, enfrenta o tema da pessoa trans, adotando não somente o caráter biológico, mas levando em conta o sexo psíquico e o gênero evidenciado, sendo esses três conceitos essenciais para a conclusão do espaço que as mulheres trans devem ocupar em sociedade. Portanto, quando o sexo psíquico e o gênero vivenciado na sociedade são contrários ao biológico, esses dois primeiros devem prevalecer.

Conforme afirma Cazelatto e Cardin (2019), é a partir da produção dos signos e das funções tidas como femininas ou masculinas, bem como das práticas culturais estereotipadas e padronizadas que envolvem a sexualidade, que o indivíduo, enquanto um ser social, padroniza-se para ser aceito e reconhecido na sociedade.

O sexo biológico é algo frágil e essa afirmativa pode ser facilmente comprovada partindo do princípio de que independentemente da genitália que a pessoa possui, o gênero será determinado pela postura social do indivíduo perante a sociedade. As expressões corporais, roupas, acessórios e adereços utilizados levam a concluir quais anseios este corpo vivencia. Logo, os gêneros masculino e feminino são, ao mesmo tempo, de fácil constatação, mas de difícil conceituação, pois são determinados por diversos fatores.

Partindo disso, já que está conceituado o perfil da mulher trans frente ao espaço que esta ocupa, deve ser também analisada a violência transfóbica que essas mulheres enfrentam diariamente.

Para identificar uma expressão transfóbica, deve ser analisado seu cometimento com base na motivação a partir de características de grupos LGBT+, em que mesmo que o ataque seja direcionado a uma única pessoa, quando o fator de motivação do agente for o sentimento transfóbico, isto é, aversão aos papéis culturais atribuídos ao sexo, ao gênero, à identidade de gênero e à orientação afetivo-sexual, este ato não será um mero insulto pessoal [..] (CAZELATTO; CARDIN, 2019, p. 564).

Portanto, a transfobia se identifica diante do ódio ao gênero evidenciado à mulher transgênero, onde em uma relação íntima de afeto, seja com o namorado, companheiro ou ex-namorado, a mulher transgênero está protegida pela Lei Maria da Penha, pois também é vulnerável se a violência ocorre no ambiente 
familiar ou em razão de relações afetivas o agressor que cometeu crime. Assim,

a Lei Maria da Penha não trata de qualquer modalidade de violência contra a mulher, mas somente daquela baseada no gênero, $[. .$.$] o conceito de mulher trazidos pela lei$ suplanta o perfil biológico (sexo feminino; sexo masculino) para alcançar a concepção sociológica do gênero. $\mathrm{Na}$ identificação dos destinatários da Lei todas essas questões devem ser analisadas. (BIANCHINI, 2014, p. 420).

A aplicação da Lei Maria da Penha tem por peculiaridade a qualidade especial da vítima de ser mulher, nesse sentido, Maria Berenice Dias disserta que lésbicas, transexuais, travestis e transgêneros que tenham identidade social baseada no sexo feminino, também estão sob a égide da proteção da Lei Maria da Penha. A agressão contra elas, no âmbito familiar, constitui violência doméstica. Diante disso, descabe deixar à margem da proteção legal aqueles que se reconhecem como mulher (SÁ JUNIOR, 2019).

Para que ser aplicada a Lei Maria da Penha também para a proteção das mulheres trans, é primordial que reste comprovada a convivência familiar, a motivação de gênero e a posição de vulnerabilidade perante seu agressor. (SÁ JUNIOR, 2019). Portanto, mulheres trans devem ser abarcadas pela Lei Maria da Penha, pois, conforme evidenciado, ao assumirem a expressão de gênero perante a sociedade, adquirem todos os direitos inerentes à condição de mulher. Agir na contramão disso violaria vários preceitos fundamentais, dentre eles, a dignidade da pessoa humana.

\section{REEDUCAÇÃO CULTURAL}

Além das questões levantadas, deve-se entender que a educação é o principal instrumento de combate à violência doméstica. Meninos e meninas devem compreender que são iguais em potencialidades e habilidades mesmo com diferenças físicas. É necessário combater o machismo enraizado na nossa cultura.

Como compreende Maria Helena Simón Rodríguez: (2015, p. 218-219).

El derecho carece aún de conceptos para incluir a las mujeres como iguales, la educación no habla con ellas ni de ellas, la ciencia no las toma como paradigma de lo humano, El periodismo no les concede el lugar ni el trato que les corresponde, la cultura las trata como cuerpos sexuales y poco más, y el lenguaje las minusvalora, las oculta y juega con el femenino, como término marcado y de forma ambígua: incluyéndolas o excluyéndolas sin indícios 
ni razones suficientes para hacerlo. Y, por eso también, el concepto de igualdad, cuyo discurso ha tenido y tiene bastante buena acogida social, se desangra por lós flancos más vulnerables, deriva y sufre un lifting, mostrando un rostro irreconocible.

Por conseguinte, o empoderamento feminino deve ser incentivado desde a infância, como forma de garantir às mulheres maior autonomia e autodeterminação, pois grande parte das meninas acreditam ser menos inteligente, ou capazes que os meninos. Nesse sentido, Larissa Amorim Borges (2016), Subsecretária de Políticas para as Mulheres da Secretaria de Estado de Direitos Humanos, Participação Social e Cidadania (Sedpac), acredita que isso se deve ao fato de as meninas serem educadas para serem submissas aos homens, uma vez que ainda vivemos em uma sociedade machista.

O estímulo deve partir dos pais para com as filhas, que devem influenciar e elevar a sua autoestima, para que esta criança se torne uma mulher confiante, que faça aquilo que mais deseja, sabendo do seu próprio valor.

Os homens, quando crianças, não podem mais serem criados diante da velha visão de que as mulheres são como um objeto. A objetificação faz com que eles, desde criança, se sintam no poder de excluírem os sentimentos e desejos femininos, o que na fase adulta crescerá, tornando-os homens abusivos.

Estimulando o empoderamento, haverá uma colaboração para o desenvolvimento da sociedade. Vale ressaltar que o Brasil é um dos países onde se é mais difícil ser mulher e isso se dá muito em razão das desigualdades sociais que intensificam nossas vidas. Consequentemente, há a construção de uma forma de convivência que deteriora as relações humanas como um todo, porque o machismo não é prejudicial só para as mulheres, mas para os homens também.

A prática do respeito desde a infância possui o condão de formar famílias com menos casos de violência, pois um homem que reconhece a humanidade e a igualdade da mulher, e que respeita isso, saberá conviver sem praticar atos violentos.

\subsection{Prevenção social}

A prevenção é considerada um dos modos mais eficazes contra os atos violentos dentro das famílias brasileiras. Como conclui a pesquisadora britânica Fiona Macaulay (2016):

É possível prevenir, mas tem de haver um enfoque além da polícia. A prevenção começa com as normas da sociedade e elas se estabelecem primeiro na escola, e tem de ser trabalhado de uma forma muito competente e contí- 
nua. Tem de trabalhar de uma forma afetiva com meninos e meninas sobre relacionamentos e reconhecimento de emoções. Sei que nesse momento no Brasil a questão da educação pública é um assunto politizado. Geralmente, as pessoas não entendem sequer o significado da palavra gênero, mas há relação com as normas sociais que dirigem e formam o comportamento. Todos nós sabemos que há uma tolerância social à violência doméstica e, a violência nasce dessas normas. Essa tolerância se expressa de diferentes formas. A prevenção é completamente atingível, mas tem de ser de uma forma continuada, baseada em muita pesquisa, e depois tem de investir na avaliação dessa política pública, senão nunca se descobrirá se está havendo impacto ou não. (CARVALHO, 2016).

Apenas quando o problema da violência doméstica deixar de ser visto como pessoal e alcançar o status de problema social, é que atingirá a necessária visibilidade. Esta nova percepção, trará, além do empoderamento da mulher, a urgência da proteção da mulher na família e na sociedade, fazendo com que o padrão de um relacionamento abusivo, entre os sexos, seja visto como um obstáculo à completa igualdade e desenvolvimento social.

Dessa forma, para prevenir a violência contra a mulher devemos compreender o que é violência. Sabe-se que nem toda violência é visível e, por isso, devem ser criadas políticas de enfrentamento dentro da saúde pública para que sejam captados todos os sinais de ocorrência de maus-tratos, trazendo mais possibilidades de visibilidade e aumentando as chances das intervenções. Outra estratégia se dá por meio de campanhas de mobilização social da importância da notificação da violência, que deve ser compreendida como meio de proteção aos direitos das mulheres, assim como os de seus filhos.

As escolas, como formadoras de seres pensantes e lugar onde os menores passam grande parte do seu tempo, devem, além de discutir a temática, dar atenção maior aos alunos, pois, muitas vezes, eles estarão emitindo sinais com pedidos de socorro, esperando que seus professores ou orientadores percebam e os ajudem com a violência sofrida ou vivenciada no seio familiar.

Assim, a complexidade do fenômeno em questão nos faz destacar a necessidade de práticas educativas como ferramenta de enfretamento e combate a toda forma de violência.

A violência doméstica se dá no âmbito doméstico e familiar e, por ser cometida no contexto das relações íntimas, deveria ser uma condição agravante de pena, por ser um crime cometido de forma privilegiada, visto que a vítima é um alvo acessível em um ambiente favorável ao agressor. Portanto, por mais que o país apresente inúmeras formas de coibir a violência doméstica, a grande luta 
que se trava na atualidade não gira em volta da conquista literal de direitos, mas em torno de mecanismos que garantam a sua aplicabilidade.

\section{CONSIDERAÇÕES FINAIS}

A criação da Lei Maria da Penha, Lei 11.340/2006, foi um dos grandes progressos na luta contra a violência contra a mulher em meio a uma sociedade culturalmente machista. Contudo, para que se torne plenamente eficaz e que haja um efeito visível dentro do que a lei determina, deve haver o investimento do Estado em uma maior capacitação dos agentes responsáveis pelo atendimento à mulher, com fulcro no artigo 10 - A, da Lei Maria da Penha.

De igual modo, vê-se a necessidade de intensificação da discussão de gênero, incluindo a violência contra a mulher nas escolas e nos espaços educacionais, pois assim o Estado estaria exercendo sua função social de proteção da cidadania dos alunos. No âmbito familiar, os pais devem criar uma estrutura que ensine os filhos a respeitar o potencial feminino e o valor da mulher, sem torná-la um objeto, reconhecendo-a como um sujeito de direito.

Ademais, ficou constatado no decorrer desse estudo que a Lei Maria da Penha se aplica também às mulheres trans, pois a Medicina e a Psicologia já as reconhecem como mulheres e o direito já segue esse entendimento. O Estado, como um agente protetor e portador da justiça e da possibilidade de segurança à mulher, deve tomar para si a responsabilidade de intervir, prevenir e combater todos os meios de violência doméstica, pois este é um crime cruel e de difícil percepção, que envolve não somente a violência em si, mas o afeto e a relação entre o agressor e a vítima, tornando a situação ainda mais difícil de ser contornada. Por isso, o amparo familiar, não somente financeiro, mas psicológico às vítimas, é de extrema relevância.

\section{REFERÊNCIAS}

ALMEIDA, T. M. C. de; BANDEIRA, L. A violência contra as mulheres: um problema coletivo e persistente. In: LEOCÁDIO, E.; LIBARDONI, M. (org.). O desafio de construir redes de atenção às mulheres em situação de violência. Brasília: AGENDE, 2006, p.19-43.

BATISTA, N. Introdução Crítica ao Direito Penal Brasileiro. Rio de Janeiro: Revan, 2001.

BRASIL, Lei ${ }^{0} 11.340$, de 07 de agosto de 2006. Cria mecanismos para coibir a violência doméstica e familiar contra a mulher, nos termos do $\S 8^{\circ}$ do art. 226 
da Constituição Federal, da Convenção sobre a Eliminação de Todas as Formas de Discriminação contra as Mulheres e da Convenção Interamericana para Prevenir, Punir e Erradicar a Violência contra a Mulher; dispõe sobre a criação dos Juizados de Violência Doméstica e Familiar contra a Mulher; altera o Código de Processo Penal, o Código Penal e a Lei de Execução Penal; e dá outras providências. Diário Oficial da República Federativa do Brasil, Brasília, DF, p. 1-4, 08 ago. 2006, Seção 1.

BRASIL, Lei $n^{0} 13.505$, de 08 de novembro de 2017. Acrescenta dispositivos à Lei no 11.340, de 7 de agosto de 2006 (Lei Maria da Penha), para dispor sobre o direito da mulher em situação de violência doméstica e familiar de ter atendimento policial e pericial especializado, ininterrupto e prestado, preferencialmente, por servidores do sexo feminino. Diário Oficial da República Federativa do Brasil, Brasília, DF, n. 215, p. 1, 09 nov. 2017, Seção 1.

BEAUVOIR, S. de. O segundo sexo. Rio de Janeiro: Nova Fronteira, 2000.

BIANCHINI, A. Aplicação da lei maria da penha a transexual e homossexual? In: DIAS, M. B. Diversidade sexual e direito homoafetivo. (coord.). 2. ed. São Paulo: Revista dos Tribunais, 2014.

BIROLI, F. Gêneros e desigualdades: limites da democracia no Brasil. São Paulo: Boitempo Editorial, 2018.

CARVALHO, M. A. 'Prevenção contra a mulher deve começar na escola'. Estadão, São Paulo, 25 set. 2016. Disponível em: http://brasil.estadao.com.br/ noticias/geral,prevencao-a-violencia-contra-a-mulher-deve-comecar-na-escola,10000078074. Acesso em: 22 mar. 2018.

CAZELATTO, C. E. C.; CARDIN, V. S. G. Discurso de ódio e minorias sexuais. Rio de Janeiro: Lumen Juris, 2018. 156 p.

CAZELATTO, C. E. C.; CARDIN, V. S. G. Do Discurso de ódio e o direito à vida dos transgêneros. In: VIEIRA, T. R. (org.). Transgêneros. Brasília: Zakarewicz, 2019. p. 563-582.

JENAINATI, C.; GROVES, J. Feminismo: Una guía ilustrada. Madrid: Tecnos, 2018.

MENDONÇA, Renata. Violência doméstica: 5 obstáculos que mulheres enfrentam para denunciar. BBC Brasil em São Paulo. Edição de 10 dez. 2015. 
MIRANDA, I. “Em briga de marido e mulher ninguém mete a colher?": Uma análise das políticas criminais de violência doméstica sob a perspectiva da criminologia crítica e feminista. Rio de Janeiro: Lumen Juris, 2016.

RODRÍGUEZ, M. E. S. Dónde estás, feminismo? Cambiaste nuestras vidas? In: MAGDA, R. M. R. (ed.). Sin género de dudas: logros y desafios del feminismo hoy. Madrid: Biblioteca Nueva, 2015, p. 203-234.

SÁ JUNIOR, L. I. N. Aplicabilidade da Lei Maria da Penha em caso de violência contra a mulher transgênero. In: VIEIRA, T. R. (org.). Transgêneros. Brasília, DF: Zakarewicz, 2019, p. 613-627.

WALKER, L. The battered woman, Nova Iorque: Harper Perennial, 1979.

ZAFFARONI, E. R. Em busca das penas perdidas: a perda da legitimidade do sistema penal. Rio de Janeiro: Revan, 1991. 